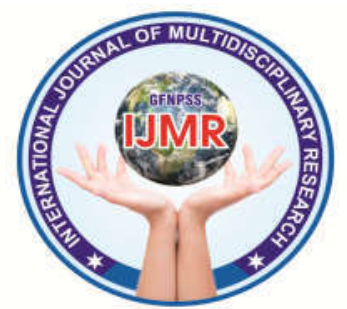

\title{
AGE ESTIMATION BY MEASURING OPEN APICES OF PERMANENT TEETH AMONG 6-10 YEARS OLD - A DIGITAL ORTHOPANTOMOGRAPH STUDY IN HARAUTI REGION
}

\section{DR. MANISH GOEL ${ }^{1}$ DR. SRINANDAN PRADHAN ${ }^{2}$ DR. HARSIMRAN SINGH $^{3}$ DR. SAKSHI MALIK ${ }^{4}$ DR. RUBAAB CHHINA ${ }^{5}$ DR. NOVINA CHETTRI $^{6}$}

\footnotetext{
${ }^{1}$ Prof \& Hod Department of Pedodontics \& Preventive Dentistry, Daswani Dental College and Research Centre. Kota, Rajasthan.

${ }^{2}$ Senior Lecturer, Department of Pedodontics \& Preventive Dentistry, Daswani Dental College and Research Centre. Kota, Rajasthan.

${ }^{3}$ Reader Department of Pedodontics \& Preventive Dentistry ,Daswani Dental College and Research Centre Kota, Rajasthan.

${ }^{4}$ Reader, Department of Pedodontics \& Preventive Dentistry, Daswani Dental College and Research Centre. Kota, Rajasthan.

${ }^{5}$ Senior Lecturer, Department of Pedodontics \& preventive dentistry daswani dental college and research centre. kota, rajasthan.

${ }^{6} \mathrm{pg} 2^{\text {nd }}$ Year, Department of Pedodontics \& Preventive Dentistry, Daswani Dental College and Research Centre. Kota, Rajasthan.

Corresponding Email: samratnandu@gmail.com
}

\section{ABSTRACT:}

Background: To calculate maturity andage estimation, stages of teeth formation is commonly used tool for age estimation of a individual. This evidence assist in diagnosis and treatment planning in clinical as well as in forensic dentistry. Dental age estimation is based on morphological, histological, biochemical and radiological measurement of teeth.

Materials and Methods: A retrospective observational study included - a total of 96 panoramic radiographs of patients aged $6-10$ years. The mean length of teeth and width of open apices of seven right or left mandibular teeth were calculated using radiovisiography and adobe photoshop software.

Results: The linear regression equation derived for estimation of age, from the variables X1, $\mathrm{X} 2, \quad \mathrm{X} 3, \mathrm{X} 4, \mathrm{X} 5, \quad \mathrm{X} 6, \mathrm{X} 7, \quad \mathrm{~s} \quad \& \quad \mathrm{~N}, \quad$ was $10.145-0.703 \mathrm{~S}+0.208 \mathrm{~S} . \mathrm{N}-0.600 \mathrm{X} 5$. Conclusion:Cameriere's method can be used for age assessment in children in case of forensic as well as legal contexts and based on these variables a reliable age estimation equation was proposed specifically for Rohilkhand region population. 


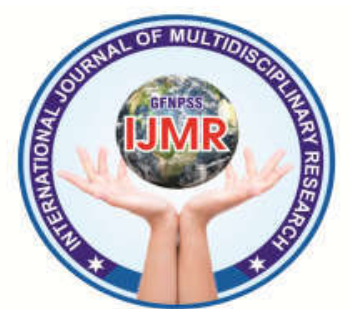

Keywords: Cameriere Method, Regression, Equation, Forensic Dentistry,Panoramic Radiograph

\section{INTRODUCTION}

Assessment of age in children is the elementary query in forensic medicine, paediatric and in orthodontic treatment. Age is defined as a period of human life, measured by years from birth; it is an important religious, social, and cultural phenomenon. Forensic dentistry plays a vital role in the implementing dental knowledge to those criminal and civil laws who are captured by police agencies in a criminal justice system. ${ }^{[1]}$ In judiciary forensic dentistry plays a vital role in implementing dental knowledge on criminals captured by police agencies. It is more relevant in our country, where significant number of children and adolescents don't own any identification entity. ${ }^{[2,3]}$

In a growing individual, to estimate the age - skeletal, odontological, anthropological and psychological methods are used. The commonly used for skeletal maturity are those concerning the left hand-wrist area (e.g. TannerWhitehouse $^{[4]}$ and FELS $^{[5]}$ methods), which can estimates the age up to 16 years, at which time wrist maturation is complete in $90 \%$ of subjects. ${ }^{[3]}$
Among the various system developed to determine dental age, Demirjian ${ }^{[6]}$ system has gained wide acceptance. Earlier, Koshy $\mathrm{S}$ et al., and Anand $\mathrm{K}$ et al., checked the applicability of this method in Indian population and found an overestimation of age, hence they concluded that it cannot be applied for Indian children. ${ }^{[7,8]}$ In 2006, Cameriere et al developed a new method for assessing chronological age in children based on the relationship between age and measurement of open apices in teeth. ${ }^{[9]}$ Bagh $\mathrm{T}$ et al., conducted a study by using the aforementioned method and a Cameriere's formula specific for Indian children was established. ${ }^{[10]}$ But due to its rich culture variability \& mixed ethnicity, in India there is need for region specific formula. Hence the present study was designed to evaluate the viability of Cameriere's specific formula for India population at Kota district of Harauti region.

\section{Research Hypothesis}

There will be a correlation between the age estimated by measuring the open apices of teeth and the chronological age of the patient. 
Materials and Methods

A total of 96 Orthopantomographs

(OPGs) of age groups 6 - 10 years comprising both sexes were selected from the department of Pedodontics and preventive dentistry.

Inclusion Criteria:

- Healthy children of Kota district of Harauti regionorigin in the age group of 6-10 years

- All teeth on the right or left lower jaw should be present,

- Accurate Orthopantomograph showing full complement of teeth without any pathologies.

Exclusion Criteria:

- Children with any systemic diseases, hereditary diseases affecting the dentofacial complex, congenital anomalies and presenting with any syndromes and under any medication which affect development.

- Children un co-operative for radiographic procedures.

- Patients undergoing radio/chemo therapy for head and neck malignancies.

- Radiographs that are unclear and show any pathology on the concerned side of the lower jaw like developmental abnormalities, grossly decayed teeth, tooth fractures, cysts or tumors.

Procedure:

As per indication, OPG were taken as a part of routine investigation. Approval from the ethical committee of the institution was obtained and the study was designed in accordance to the revised Helsinki declaration (2013). After elaborate case history taking for each individual ,date of birth was cross confirmed with the appropriate certificate. For each individual the chronological age was calculated by subtracting the birth date from the date on which radiograph was exposed for that particular patient. The images were processed using a computer-aided drafting program, Adobe Photoshop Software (version 7.0) and the following parameters were calculated with the measuring tool present on the dropdown column on the left-hand side of the screen.

Images of seven left or right permanent mandibular teeth were assessed. Number of teeth with complete root development and completely closed apices of the roots $(\mathrm{N})$ were calculated. Also, teeth with incomplete root development and therefore with open apices were also examined. For teeth with one root, 


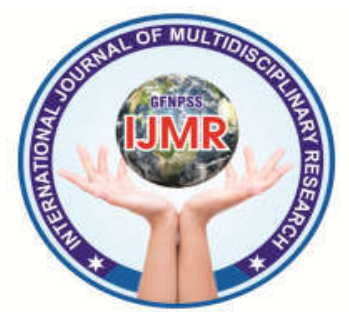

distance Ai, where $(\mathrm{i}=1,2,3,4,5): 1$ morphological variables and subjects' central incisor, 2 - lateral incisor, 3 gender and nationality, a multiple linear canine, 4 - first premolar, 5 - second premolar. For teeth with two roots, the sum of distance between inner sides of two open apices was calculated and denoted as Ai $(i=6,7) ; 6$ - first molar, 7 - second molar.(Figure 1)

In the present study, two observers had estimated and calculated the open apices of all the seven left or right permanent mandibular teeth.

Due to possible difference in magnification and angulation among $\mathrm{X}$-ray measurements, $\mathrm{Ai}$ was normalized by dividing it with tooth length. Tooth length was measured from point of highest cusp to the root apex and was denoted as Li. Dental maturity was evaluated using normalized measurements of seven right or left mandibular teeth as $\mathrm{Xi}=\mathrm{Ai} / \mathrm{Li} ; \mathrm{i}=1$ to 7. Therefore, sum of normalized open apices was calculated as $\mathrm{S}=\mathrm{X} 1+\mathrm{X} 2+$ $\mathrm{X} 3+\ldots+\mathrm{X} 7$.

\section{Statistical Analysis}

All the morphologic variables were entered in an Excel file and were used as predictive variables for age estimation in sequential statistical analysis. To obtain an estimate of age as a function of the

regression model with first-order interactions was developed by selecting those variables that contributed significantly to age estimations using the stepwise selection method. Analysis of covariance was then applied to study, possible interactions between significant morphological variables and gender. Statistical analysis was performed with SPLUS 6 statistical programs (S-PLUS 6.1 for Windows). The significance threshold was set at $5 \%$.

\section{RESULTS}

A total of 96 Orthopantomographs (OPGs) of age groups 6 to 10 years comprising both sexes were selected. (Table 1)

There were no statistically significant intra-observer differences between the paired sets of measurements carried out on the re-examined panoramic radiographs. All correlation coefficients between age and morphological variables were significant and negative. (Table 2). Subjects' age was modelled as a function of the morphological variables (predictors), and to optimize the model, a stepwise regression procedure was applied. 


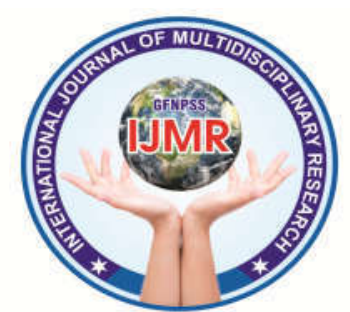

The results (Table 3) show that the variables X5 (second premolar), $\mathrm{S}, \mathrm{N}$ and the first order interaction between $\mathrm{S}$ and $\mathrm{N}$ contributed significantly to the fit. tipping or impaction of teeth. It is commonly seen during the developmental stages particularly in root formation, a distinguish difference exist between sexes Thus, only these variables were included in the regression model, yielding the following linear regression formula:

Age $=10.145-0.703 \mathrm{~S}+0.208 \mathrm{~S} . \mathrm{N}-$ $0.600 \times 5$

The residual plot (Graph 1) shows no obvious pattern, and Scatter Plot of Observed cumulative probability Value and expected cumulative probability value showing that regression model fits the trend of data very well.

The Scatter Plot (Graph 2) of fitted value and observed value again showing that regression model fits the trend of data reasonably well and Scatter Plot (Graph 3) of Residuals against fitted value showing no obvious pattern.

\section{DISCUSSION}

The growth of child is affected by various factors (ethnic, nutritional, socioeconomic status etc.). Nevertheless, the different methods of age estimation based on teeth do not provide a common formula for the whole world. ${ }^{[10]}$

Eruption of tooth is influenced by many factors such as space in the dental arch, extraction of deciduous predecessors 


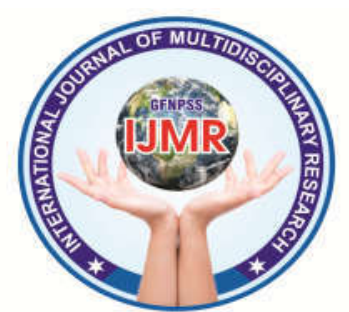

most other methods for age estimation and is most commonly used to determine age in living humans. ${ }^{[3]}$

Several studies show that morphological measurements can be consistently made in panoramic radiography, provided that some corrections are made to take into account the individual variability of tooth size and the differences in magnification of radiographs and angulation between $\mathrm{x}$-ray beam and film. ${ }^{[3]}$

In Harauti region, the Indiaspecific formula cannot be applied. Hence in current study OPGs have taken for the individual belonging to Harauti itself.

The radiological method is amongst one of the most reliable method available for age estimation which is extensively used for both dental and skeletal method. ${ }^{[13,14,15]}$ In the current study dental age had been assessed by using Panoramic radiograph, following the method described by Cameriere, which is widely accepted and has been studied extensively on various population by many authors. ${ }^{[3,10]}$

Study was done by Cameriere L et al on Italian population of children aged between 5-15 years. Study based on seven mandibular left healthy permanent teeth for assessing dental age by measurement of open apices in teeth. Statistical analysis showed a significant correlation with chronological age, morphological variables explain $83.6 \%(\mathrm{R} 2=0.836) .{ }^{[3]}$ In our study, statistical analysis indicated that gender does not have a significant influence on age estimation. $\left(\mathrm{R}^{2}=0.956\right)$.

Cameriere $\mathrm{L}$ et al had derived a common formula for children from European background. Their results showed that the median of the absolute value of residual errors were 0.035 years. $^{[16]}$ In the present study, results showed that the median residual errors were 0.0024 years.

In parallel to the current study in which gender did not have a significant influence on age estimation. $\left(\mathrm{R}^{2}=0.956\right)$ ,Rai $B$ et al showed a significant correlation with chronological age except gender and second premolar, these morphological variables explain $89.7 \%$ ( $\mathrm{R} 2=0.897)$ variations in estimated dental age ${ }^{[10]}$ by using modified Cameriere's European formula.

By using Cameriere's regression equation on the age group of 5-15 years ,in Haryana sub-population Kaur $\mathrm{J}$ et al detected underestimation of age in boys and overestimation in girls as related to their chronological age. ${ }^{[17]}$ But in present 


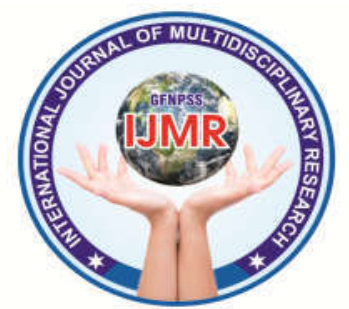

study, gender did not have a significant influence on age estimation.

Resulting the current study showed that not all the variables used for the European and Indian models were significant predictors of age estimation in the Rohilkhand sample.

The results found in this work, indicates that more attention should be focused on the possible differences between children of different origins. Further studies will be carried out to apply Cameriere's formula to a new Indian sample, to test a new Asian sample, and to study the effects of the nutrition factor on the Indian formula.

\begin{tabular}{|c|c|c|c|}
\hline $\begin{array}{c}\text { Age } \\
\text { (years) }\end{array}$ & Male & Female & Total \\
\hline 6 & 14 & 14 & 28 \\
\hline 7 & 13 & 7 & 20 \\
\hline 8 & 13 & 3 & 16 \\
\hline 9 & 6 & 7 & 13 \\
\hline 10 & 13 & 6 & 19 \\
\hline Total & 59 & 37 & 96 \\
\hline
\end{tabular}

Table 1: Distribution of study subjects in age and gender

\begin{tabular}{|l|c|c|}
\hline \multicolumn{1}{|c|}{ Regression Analysis } & t value & P \\
\hline Intercept & 70.797 & $<0.001$ \\
\hline Gender & 1.240 & 0.218 \\
\hline $\begin{array}{l}\text { Dental maturity of } \\
\text { second premolar (X5) }\end{array}$ & -1.945 & 0.055 \\
\hline $\begin{array}{l}\text { Sum of normalized } \\
\text { open apices (S) }\end{array}$ & 12.918 & $<0.001$ \\
\hline $\begin{array}{l}\text { Number of teeth with } \\
\text { complete root } \\
\text { development (N) }\end{array}$ & -0.021 & 0.983 \\
\hline $\begin{array}{l}\text { Interaction between s } \\
\text { and N }\end{array}$ & 1.644 & 0.104 \\
\hline
\end{tabular}

Table 2: Regression analysis predicting Chronological age for Rohilkhand region

\begin{tabular}{|l|c|c|}
\hline $\begin{array}{c}\text { Stepwise Regression } \\
\text { Analysis }\end{array}$ & t value & P \\
\hline Intercept & 95.265 & $<0.001$ \\
\hline $\begin{array}{l}\text { Sum of normalized } \\
\text { open apices (S) }\end{array}$ & -13.046 & $<0.001$ \\
\hline $\begin{array}{l}\text { Interaction between s } \\
\text { and N }\end{array}$ & 5.268 & $<0.001$ \\
\hline $\begin{array}{l}\text { Dental maturity of } \\
\text { second premolar (X5) }\end{array}$ & -2.092 & 0.039 \\
\hline $\begin{array}{l}\text { Table 3: Stepwise Regression analysis for } \\
\text { predicting chronological age } \\
\text { Rohilkhand region } \\
\text { for }\end{array}$ \\
\hline
\end{tabular}




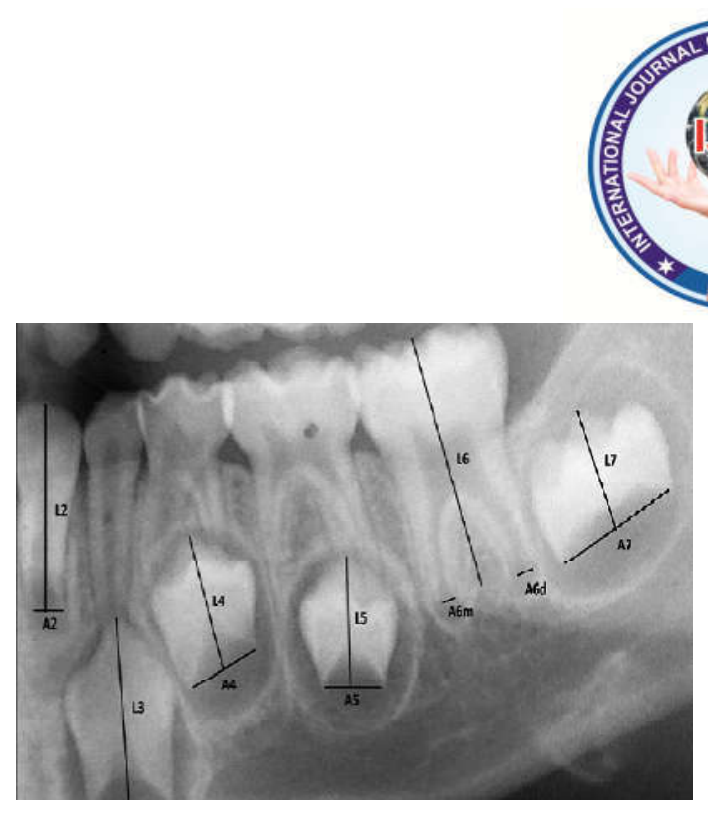

Figure 1: An example of tooth measurement in Adobe Photoshop. Ai, i = $1, \ldots, 5$ (teeth with one root), is distance between inner sides of open apex; Ai, $i=6$ and 7 (teeth with two roots), is sum of distances between inner sides of two open apices; and $\mathrm{Li}, \mathrm{i}=1, \ldots, 7$, is length of seven teeth.

\section{Normal P-P Plot of Regression Standardized Residual}

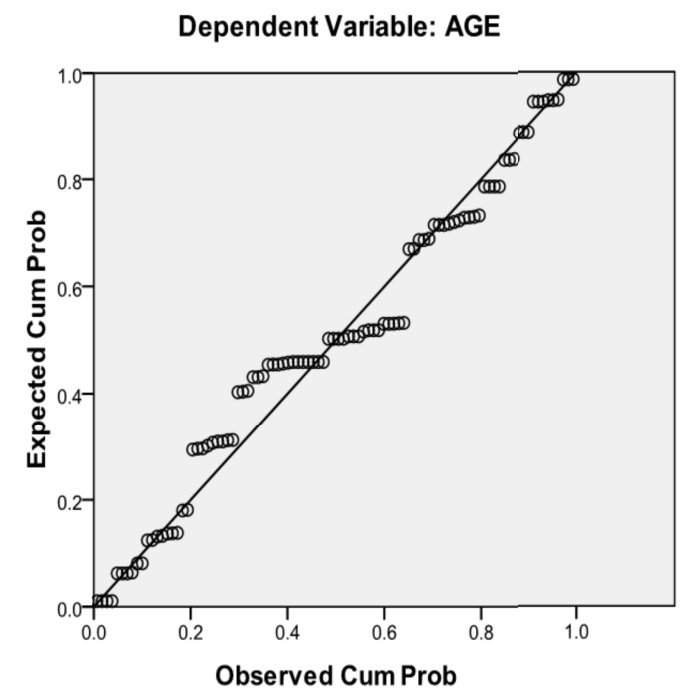

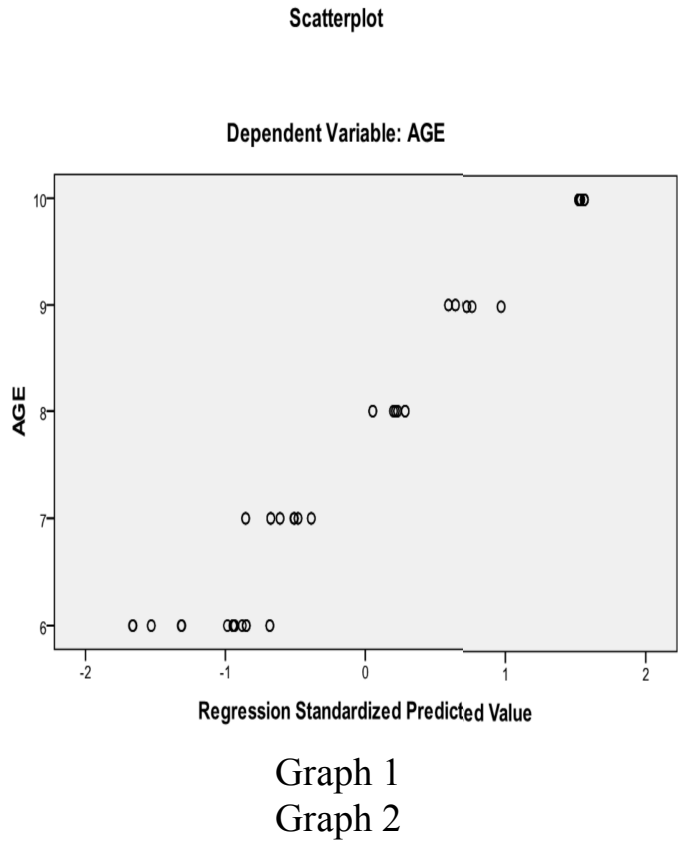

Graph 1 \& 2: Plots of expected cum probability against observed cum probability, and age against regression standardized predicted value respectively.

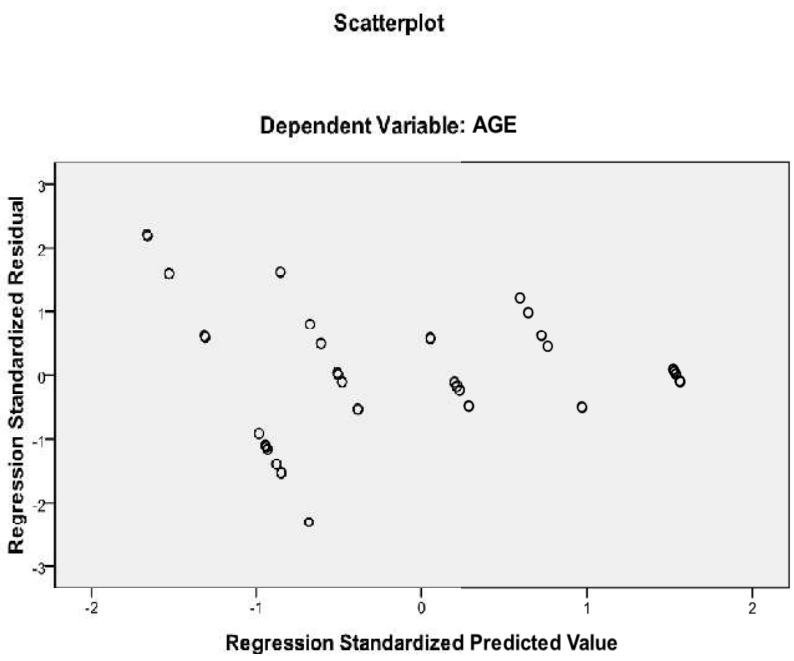

Graph 3: Plots of regression standardized residuals against regression standardized predicted value. 


\section{CONCLUSION}

In the present study we found a very good correlation between the Chronologic and dental age. Results indicated the suitability of the sum of normalized open apices (s) and number (N0) of teeth with complete root development as developmental markers. We have also come up with a linear regression equation for both males and females which can be used in order to decrease the gap between the Chronologic age and dental age, so that a relative approximate age can be obtained. Since our study has a small sample size we were not able to give the exact value of variation between each age group that the chronological and dental method assessed. The present Regression equation is derived for age estimation fromHarauti region, children.

\section{REFERENCES}

1. Verma K, Joshi B, Joshi CH, Reject Paul MP. Bite Marks as Physical Evidence from the Crime Scene-An Overview. 2013;2(1):1-6.

2. Luca DS, Giorgio DS, Butti CA, Biagi R, Cingolani M, Cameriere R. Age estimation in children by measurement of open apices in tooth roots: study of
Mexican sample. Forensic Sci Int 2012; 221(1-3):155-157.

3. Cameriere R, Ferrante L, Cingolani M. Age estimation in children by measurement of open apices in teeth. Int J Leg Med 2006;120(1):49-52.

4. Tanner JM, Healy MJR, Goldstein H, Cameron N. Assessment of skeletal maturity and prediction of adults height (TW3 Method). Saunders, London 2001.

5. Roche AF, Cameron Chumlea W, Thissen D. Assessing the skeletal maturity of the hand-wrist: FELS method. Charles C. Thomas Publisher, Springfield 1988.

6. Demirjian A, Goldstein H, Tanner JM. A new system of dental age assessment. Human biology 1973;45(2):211-27.

7. Koshy S, Tandon S. Dental age assessment: the applicability of Demirjian's method in South Indian children. Forensic Sci Int 1998;94(12):73-85.

8. Anand K, Kant S, Kapoor SK. Nutritional status of adolescent school children in rural north India. Indian pediatrics. 1999;36:810-816.

9. Cameriere R, Ferrante L, Liversidge HM, Prieto JL, Brkic H. Accuracy of 


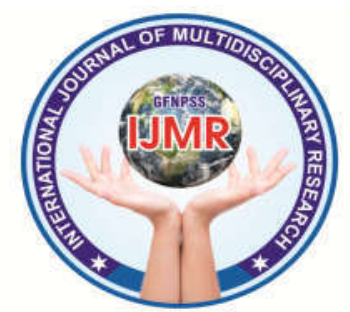

age estimation in children using

World Journal of Medical Sci radiograph of developing teeth. 2006:1(2);130-132.

Forensic Sci Int. 2008;176(2-3):173-7.

14. Rai B, Anand SC. Age estimation in

10. Rai B, Kaur J, Cingolani M, Ferrante L, Cameriere R. Age estimation in children by measurement of open apices in teeth: an Indian formula. Int. Journal of Legal Medicine; 2010;124(3):237-241.

11. Bagh T, Chatra L, Shenai P, Veena KM, Rao PK, Prabhu RV, Kushraj T, Shetthy P. Age Estimation using Cameriere's Seven Teeth Method with Indian Specific Formula in South Indian Children. Int J Adv Health Sci 2014;1(2):2-10.

12. Fernandes MM, Tinoco RLR, Braganca DPB, Lima SHR, Junior LF, Junior ED. Age estimation by measurements of developing teeth: accuracy of Cameriere's method on Brazilian sample. J Forensic Sci 201;56(6):1616-1619.

13. Rai B, Anand SC. Tooth developments: an accuracy of age estimation of radiographic methods. children from dental radiograph: A regression equation. Int $\mathrm{J}$ BiolAnthropol. 2008;1(2):1-5.

15. Jamroz G.M.B., Kuijpers-Jagtman A.M., Hof M.A., Katsaros C. Dental Maturation in Short and Long Facial Types: Is There a Difference? Angle Orthodontist 2006;76(5):768-772.

16. Cameriere R, De Angelis D, Ferrante L, Scarpino F, Cingolani M. Age estimation in children by measurement of open apices in teeth: a European formula. International journal of legal medicine. 2007;121(6):449-453.

17. Kaur J, Balwant R, Ferrante L, Cameriere R. Determination of Cameriere Regression Equation Accuracy for Age Estimation in Haryana sub Population: Indian Journal of Forensic Odontology. 2010;3(1):12-14. 